Instructions for authors, subscriptions and further details:

http://brac.hipatiapress.com

\title{
La Nueva Condición Transitiva de la Imagen
}

Josu Larrañaga Altuna ${ }^{1}$

1) Universidad Complutense, Madrid (España)

Date of publication: June $3^{\text {rd }}, 2016$

Edition period: June 2016 - October 2016

To cite this article: Larrañaga, J. (2016). La nueva condición transitiva de la imagen. Barcelona, Research, Art, Creation, 4(2), 121-136. doi: 10.17583/ brac.2016.1813

To link this article: http://dx.doi.org/10.17583/brac.2016.1813

\section{PLEASE SCROLL DOWN FOR ARTICLE}

The terms and conditions of use, except where otherwise noted, are related to the Open Journal System and to Creative Commons Attribution License (CCBY). The indication must be expressly stated when necessary. 
BRAC - Barcelona Research Art Creation. Vol. 4 No. 2, June 2016, pp. 121-136

\section{New Condition Transitive of the Image}

Josu Larrañaga Altuna

Complutense University, Madrid (España)

(Received: 12 November 2015; Accepted: 7 April 2016; Published: 3 June 2016)

\section{Abstract}

The combination of new devices for converting images applied to art- especially multispectral pictures, 3D-printers and scanners- and revaluation of contextual, performative and communicative aspects in the perceptual process- to the detriment of the object or the environ- underline the fragile and slipperiness of visual synthesis, and in turn, make the transitive emerging potential of every image.

Keywords: Art, image, perception, transimage 
BRAC - Barcelona Research Art Creation. Vol. 4 No. 2, June 2016, pp. 121-136

\section{La Nueva Condición Transitiva de la Imagen}

Josu Larrañaga Altuna

Universidad Complutense, Madrid (España)

(Recibido: 12 Noviembre 2015; Aceptado: 7 Abril 2016; Publicado: 3 Junio 2016)

\section{Resumen}

La combinación de los nuevos dispositivos de conversión de imágenes aplicados al arte- en especial las fotos multiespectrales, las impresoras y escáneres 3D- y la revalorización de los aspectos contextuales, performativos y comunicativos en el proceso perceptivo- en detrimento del objeto o el medio- subrayan el carácter frágil y deslizante de las síntesis visuales, mostrando a su vez la potencialidad transitiva de toda imagen

Palabras clave: Arte, imagen, percepción, transimagen 


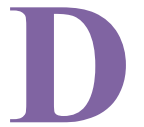

urante el otoño de 2006, la Fondazione Giorgio Cini, con el acuerdo del Museo del Louvre, encargó a la empresa FactumArte la realización de un facsímil de Las bodas de Caná, de Paolo Caliari, conocido como El Veronese. Un año después, el público que llenaba el refectorio del monasterio de San Giorgio Maggiore de Venecia podía contemplar un duplicado de la pintura, realizado mediante la combinación de fotos multiespectrales, escaneado e impresión tridimensional ${ }^{1}$.

Se trata de una transcripción de 9,55 x 6,98 metros, que reproduce fielmente aquella que los benedictinos encargaron al maestro veneciano en 1562 , y que fue requisada en 1797 por los franceses, tras la campaña de Italia, y posteriormente adquirida mediante permuta en 1815, que hoy se encuentra en París. Mientras esta, el facsímil, ocupa la pared del monasterio en la que Veronese y sus ayudantes la colgaron.

El extraordinario desarrollo de los dispositivos de conversión digito/ material, basados principalmente en la combinación de fotografía de precisión, escáneres e impresoras tridimensionales, ha permitido en los últimos tiempos la realización de facsímiles de todo tipo de obras de arte, entre ellos, un buen número de pinturas. Pero la realización e instalación de la copia de Veronese supone un gran salto cualitativo, porque por un lado nos acerca extraordinariamente a la posibilidad técnica de duplicar cualquier imagen, y por otro, nos permite comparar las condiciones perceptivas de ambas obras en relación a las previsiones de quienes pensaron, encargaron, realizaron y ubicaron la obra de arte, y por lo tanto, a la manera en que el espectador la percibe como tal.

El original se encuentra en el museo del Louvre desde 1798. Para ser trasladado desde Italia, hubo de ser desmontado, fragmentado, y posteriormente reconstruido. Desde entonces ha sido restaurado en diversas ocasiones, la última de ellas entre 1990 y $1992^{2}$. En ella participaron historiadores, comisarios, restauradores e investigadores del LRMF que radiografiaron la obra y realizaron diversos análisis estratigráficos, llevándoles a tomar distintas decisiones, algunas de las cuales supusieron la eliminación de capas de pintura $\mathrm{u}$ otras modificaciones cromáticas, en relación a lo que podían ser añadidos y restauraciones anteriores ${ }^{3}$. 
El cuadro se encuentra actualmente en la Salle des Etats frente a la Gioconda, y rodeada de pintura veneciana del siglo XVI. Considerada "la más grande y la más prestigiosa" del Museo de Louvre, la sala fue rehabilitada entre 2001 y 2005. Sus paredes están acabadas en estuco de color siena. La obra enmarcada con una moldura dorada está colgada de la pared a $70 \mathrm{~cm}$. del suelo y hasta unos cuatro metros del techo. A ambos lados se abren grandes huecos de acceso que conectan con ventanales de las paredes adyacentes. A los asistentes al museo se les encamina, por medio de carteles con una reproducción de la Gioconda y un texto que anuncia "pintura italiana", y acceden a la sala a través de estas aberturas, dando la espalda al enorme cuadro de Veronesse. La aglomeración arrastra al visitante hacia la obra de Leonardo, entre una nube de móviles y cámaras y entre cuadros de distintas dimensiones, montados en una o dos filas, que cubren los laterales de la sala. Con bastante esfuerzo, el espectador podrá darse la vuelta y volver por un costado, a contracorriente, para poder contemplar el gran cuadro de las bodas de Caná. Entonces comprobará que la escasa luz blanquecina que cae desde el techo acristalado de la sala, apenas permite identificar los colores y las formas construidos sobre el lienzo.

Nada que ver con aquella pintura pensada para adaptarse al fondo del refectorio de San Giorgio Maggiore, encajada entre la cenefa superior (que es la base del arco de la nave), y el oscuro zócalo que eleva el cuadro más de dos metros, hasta situarlo por encima del punto de vista de cualquier espectador. Nada que ver con aquella pintura (hoy esta transcripción) abrazadas y en diálogo con la arquitectura de Palladio. La conexión entre el banquete de bodas pintado y el comedor usado por los monjes, se concretaba visual y experiencialmente en el vínculo de la perspectiva con las paredes, los huecos de ventana, el techo, las mesas y los asientos donde reposaban y se alimentaban. La altura a la que se cuelga tiene que ver con esta continuidad. Y naturalmente, a la estancia se accede de frente y por el centro, y desde la habitación anterior ya puede verse al fondo la enorme pintura, enmarcada y atrapada por una habitación iluminada por amplios ventanales laterales, que la rodean de luz, y por el marco de piedra de la puerta de acceso.

Hay una enorme distancia entre pasear por las salas de un museo reformado en el XXI y recorrer un monasterio benedictino, pero en este caso además, hay unos itinerarios de acceso, una volumetría, unas condiciones espaciales, unos elementos de intermediación, una conformación cromática de las paredes y paramentos, y un tratamiento de la luz, completamente diferentes. Y hay además un contexto histórico e institucional distinto. 
$\mathrm{Si}$ "en la modernidad el museo se convirtió en un refugio para imágenes que habían perdido su lugar en el mundo, y que lo canjearon por un lugar del arte" (Belting, 2007, p.77), lo que se pone de manifiesto también, con esta nueva imagen/facsímil, es la revisión de la idea de arte en la sobremodernidad, un arte (ahora) que se aleja de la fetichización del objeto y la seguridad de su medio, para subrayar la experiencia perceptiva y las condiciones en las que puede producirse una agitación intelectiva, emotiva y sensible, en los cuerpos, en las personas, es decir, las condiciones en las que se produce aquello que llamamos recepción. Porque como dice Didi-Huberman, "las imágenes se abren y se cierran como nuestros cuerpos que la miran, es decir que las imágenes son creadas por nosotros a nuestra imagen: no solo a la imagen de nuestro aspecto, sino de nuestros actos, de nuestras crisis, de nuestros propios gestos de apertura" (Didi-Huberman, 2013, p.30).

Desde el punto de vista de la recepción, de las condiciones experienciales en las que se da a ver la misma estampa, de su instalación, estamos ante dos imágenes. Especialmente si, como afirma S. Jaschko, el espacio artístico se ha vuelto performativo, "un espacio en donde la actividad viva, el experimento procesual y el diálogo entre la obra, los artistas y sus audiencias constituyen la obra de arte. El objeto físico o el sistema continúan desempeñando un papel, pero sin que se los pueda aislar del resto de componentes del proceso" (Jaschko, 2010).

Estas dos condiciones de experiencia se manifiestan especialmente en la luz, o más certeramente, en la manera en que esta cae sobre el lienzo, es decir, la condición de la forma de lo visible, porque de acuerdo con M. Foucault (leído por G. Deleuze), "en pintura lo primero es la luz. Primero por relación a las líneas, primero por relación a los colores. Los colores y los trazos derivan de la luz, y no a la inversa. Un cuadro es ante todo un trazado de luz" (Deleuze, 2013, pp. 200 y 99). Nada que ver entre una y otra fuente de luz, pero sobre todo, nada que ver entre la manera en que en un caso se difunde y en el otro se precipita entre las formas coloreadas del lienzo.

Y lo mismo sucede con el conjunto de accesorios y ornamentos que compiten y agitan el cuerpo de la imagen en cada una de sus escenificaciones. Ese parergon a-significante y a-representativo, esos elementos que "están fuera de obra, «coadyuvantes» que no están ni afuera ni adentro" (Derrida, 2001 , pp.49 y sig.). Por ejemplo, ese marco, que es moldura en el museo y sin embargo era arquitectura en el lugar de procedencia donde la imagen se contempla mientras se contradice. El propio título (Las bodas de Caná), 
que ha sido recuperado ahora en el refectorio, en el lugar donde comían los monjes, y en consecuencia ha sido rescatado ahora para la percepción, por efecto de su reubicación en San Giorgio Maggiore.

Encontramos también diferencias fundamentales, desde el punto de vista de la recepción para los espectadores, en la disposición de sus cuerpos, en la experiencia espacio/temporal en la que pueden entrelazarse enunciados y visualidades ("cuerpo vivo, donde este debe ser entendido como cuerpo medial o «medializado»: Belting, 2007). Con el uso social de cada uno de los lugares, es decir con la actitud y el trabajo del que percibe en uno y otro caso, de sus expectativas, de sus recorridos, de los archivos de imágenes que cada una de las tentativas reclama del espectador. Y en la construcción simbólica que se ha apropiado de cada una de las instalaciones, porque ahora que tenemos un facsímil instalado en el refectorio, la obra de Veronese en el Louvre remite inmediatamente a las causas de ese desgarramiento, al hurto de Napoleón y a las intrigas del barón de Denon para no restituir la pintura a Venecia.

Nos encontramos entonces ante un cuerpo de la imagen (facsímil), cuya diferencia con el original es por un lado mínima y por otro imperceptible para el espectador. O si queremos, cuyos datos y estímulos visuales son prácticamente iguales. Y que además se encuentra en el lugar originario y en las condiciones de recepción más cercanas a las que fueron previstas por el autor. Aunque, por otro lado, como ejercicio cultural, habrá que apuntar que el consenso y la autoridad de ambas estampas, no es el mismo.

Como se ve, la irrupción de esta nueva imagen/facsímil nos plantea demasiados asuntos que no podrían ser tratados adecuadamente en un sencillo trabajo como este. De manera que deberemos centrar nuestra atención en uno de ellos: lo haremos en el de la nueva condición transitiva de la imagen, que esta historia de reproducciones, resignificaciones y emplazamientos, pone en primer término. Quizás el vertebral, porque muestra una nueva ecología de la mirada y una reconsideración de las condiciones perceptivas que producen una nueva imagen y, en consecuencia, una nueva condición de la experiencia. 

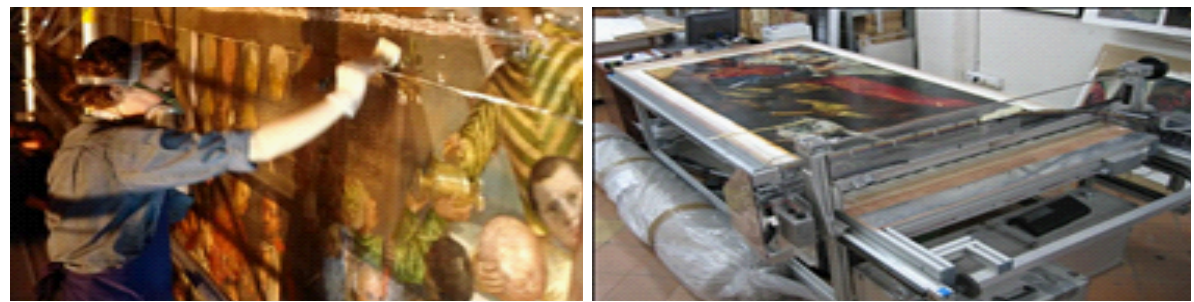

Figuras 1, 2. Izquierda: Proceso de restauración de la obra de Las bodas de Caná de Veronese, 1990-92 (fuente: Servicio de restauración de los museos de Francia). Derecha, Impresión 3D sobre lienzo preparado, de un fragmento del facsímil de Las bodas de Caná, 2006 (fuente: Factum Arte).
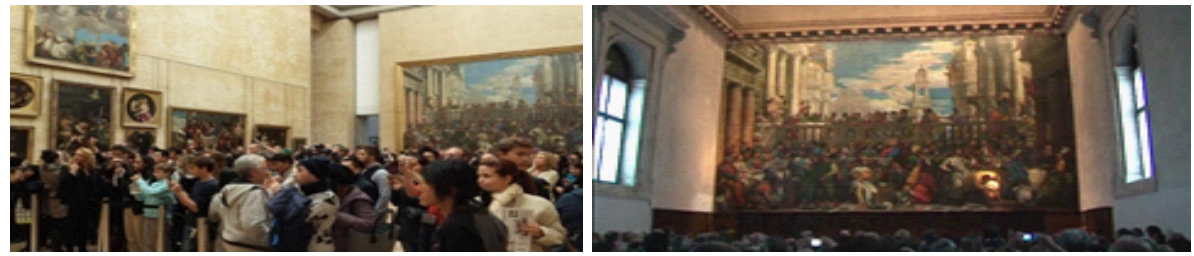

Figuras 3, 4. A la izquierda, la obra de Veronese instalada en la Salle des Etats del Museo del Louvre. A la derecha facsímil instalado en el refectorio de San Giorgio Maggiore de Venecia, el día de su presentación.

\section{Otras Imágenes}

Las imágenes actúan de una u otra manera en relación a las necesidades para las que se les reclama. Poseen esa capacidad proteica de modificar su aspecto adecuándolo a las expectativas propias de su recepción. Proteicas, por un lado, porque las imágenes están construidas mediante la combinación de cualidades paradójicas (conjuntos de aspectos materiales y virtuales, sensibles e intelectivos, visuales y táctiles, expresivos y comunicativos...) que les permiten actuar de forma diversa en contextos y escenarios múltiples, es decir, porque descansan en la condición multiforme y conversacional del proceso de elaboración de una síntesis perceptiva; por otro, porque las imágenes hacen 
suyo el flujo contingente de promesas, aportaciones, posibilidades y fantasías técnicas, enunciativas, interpretativas o tecnológicas que se producen cultural e históricamente, integrándolas en su condición imaginaria. Es así que el carácter proteico de la imagen se alimenta en una circulación de prótesis sucesivas que la atraviesan en el tiempo (Metz, 2001; Jay, 2004; Brea, 2005).

Lo visible se hace presente para nosotros adherido a un cuerpo y a un espacio/ tiempo. Tanto si ha sido vectorizado o rasterizado, reflejado o proyectado, estampado o impreso, trabado o materializado, pasa a ser una imagen para nosotros cuando se muestra como conjunto de datos visuales con posibilidad de sentido; percibidos de alguna manera, escenificados o instalados en algún lugar, y por tanto significados y mediados, dado que "la instalación indica las condiciones de legibilidad, interpretación, afección y percepción con las que esa imagen actúa en cada caso en su confrontación con el espectador; la condición en que se pone a disposición del usuario" (Larrañaga, 2011).

La imagen-materia estaba inscrita en un soporte, encarnada en los cuerpos y las cosas desde las que emergía. Las relaciones y envíos que procuraba provenían precisamente de sus cualidades esenciales de pertenencia y contigüidad. La imagen tenía cuerpo y el cuerpo tenía imagen. Y ambos eran propiamente $s u$ cuerpo y su imagen.

La fuerza de la imagen reproductiva procedía de la constatación técnica de la presencia de materias, elementos y sitios con una apariencia propia que podía ser atrapada. Las imágenes no solo describían sino que autentificaban la pertenencia de una imagen a un cuerpo, la afianzaban como verdadera muestra de aquello que significaba. Había cuerpo y sensación de pertenencia, por lo tanto. De ella tomaba la fuerza de representación, de memoria, de archivo, de retorno. La sensación de movimiento no hizo sino confirmar esta interrelación (Virilio, 1998).

Por su parte, la imagen de síntesis se hace visible en una red de pluricuerpos: El cuerpo de la imagen digital "es" la pantalla del ordenador, el monitor de televisión, los cañones y superficies de proyección, el móvil, las tabletas gráficas, las hojas de grafeno, las pantallas electrónicas de leds... o los sistemas de simulación tridimensional y los hologramas, porque es ahí donde se muestran como imágenes para nosotros. La imagen es tal cuando se usa, se percibe, manipula, difunde, intercambia... Podemos hablar de percepción en la medida en que se hace visible, se aprecia, se capta por cualquier medio. Lo que les diferencia de las épocas anteriores no es la ausencia de mediación sino precisamente su extraordinaria ubicuidad, que les permite insertarse en una multitud de situaciones y disposiciones mediante una extraordinaria 
variedad de medios. Las imágenes electrónicas y digitales se caracterizan por disponer de diversos cuerpos. Porque los dispositivos y materiales no "son", no "pertenecen" a la imagen, ni esta al cuerpo, sino que disponen y están a disposición (Yáñez Tapia, 2007).

No hay una imagen de ordenador, sino una matriz numérica almacenada y procesada en un centro de datos; una matriz que reclamamos, nombrándola, para que tome cuerpo en la pantalla de la computadora que empleamos. Porque ahora las imágenes toman cuerpos.

Ahora se hace evidente que el "soporte" soporta la imagen, es decir, no solo la sostiene sino que la fundamenta, la avala como imagen. Que las técnicas o programas que las permiten hacerse visibles, son medios portadores (Belting, 2007). Y sin embargo, la imagen no "está en otro sitio", solo está donde el usuario la reclama. Es su prototipo, su paradigma, su matriz quien se encuentra en un espacio de almacenaje de números y vectores al que no accedemos directamente.

Imagen que llamamos virtual por su posibilidad, su potencialidad, su eventualidad, no por su "inmaterialidad"; por el contrario una matriz se hace imagen para nosotros cuando se muestra en un soporte o un dispositivo de lectura, que son mucho más complejos y materiales que una delgada hoja de papel o un leve velo, por muchas sustancias adheridas que puedan incluir. Son precisamente los aparatos y medios electrónicos y las pantallas quienes conforman fundamentalmente nuestro paisaje cotidiano, nuestros hábitos, nuestra materialidad y nuestra realidad visual, imaginaria y tangible.

El uso de escáneres e impresoras bidimensionales posibilitaba un circuito cerrado por el que transitaba la idea de imagen a la espera de su materialización, porque desde los dispositivos electrónicos podíamos elaborar una matriz digital que estaba en disposición de tomar cuerpo en su impresión, y que a su vez podría incorporarse de nuevo al mundo digital mediante su escaneado... en un constante bucle. A partir de entonces, el usuario puede partir de una imagen materia para elaborar una digital y viceversa; o incluso abrir un proceso interminable de traspasos entre unas y otras- siempre y cuando se respetara la condición bidimensional y la coincidencia de sus componentes, lo que era sustancial a la imagen materia- se podría decir. Por lo tanto, se trataba de un circuito que actuaba en unos ciertos límites, pero que mostraba un nuevo ámbito de transitividad, donde la imagen podía fluctuar entre la materialidad y la virtualidad.

La invención de escáneres e impresoras tridimensionales ensanchó el circuito de forma determinante. Lo que se ha hecho visible especialmente 
en el mundo del arte. Tanto el proceso de diseño y perfeccionamiento tecnológico como el de especialización y difusión de estos dispositivos, para todo tipo de prestaciones y productos, llevan años desarrollándose a una extraordinaria velocidad. Tienen aplicaciones revolucionarias en todos los ámbitos industriales, tecnológicos, culturales y científicos.

Lo importante no es tanto si seremos capaces de duplicar una obra de arte (parece que sí) sino constatar que la distancia entre imágenes materiales y virtuales se disuelve, en beneficio de una trama de vías de circulación que aún conserva algún obstáculo pero permite el tránsito entre una y otra comprensión de la imagen (Arrault, 2006, pp.23 y sig.).

Cualquiera con conocimientos y medios suficientes puede elaborar una imagen digital o material, poco importa, e incluirla en esta trama transitiva, en la que no solo podrá ser reproducida interminablemente, sino construida tridimensionalmente en una impresora con cualquier tipo de sustancias. Porque el paso entre la materialidad y la virtualidad ya está abierto en todas direcciones. Al margen de su constitución originaria, tanto unas como otras tendrán la potencia de hacerse presentes como materia o como luz, en una extraordinaria pluralidad de condiciones y estados, porque toda estampa es susceptible de ser evaporada en una nube tecnológica transparente o fijada en la conjunción cuerpo/medio que elijamos. Lo que supone una alteración radical de aquello que llamamos imagen.

\section{Transimágenes}

La imagen es número y es materia a su vez, sea cual sea su "origen", porque posee esa potencialidad, esa posibilidad de mostrarse de una u otra forma, y por lo tanto, de ser una u otra imagen, de presentarse en uno u otro estado, en función del uso para el que se le reclama. La invención de los conversores analógico-digitales (fundamentalmente escáneres y cámaras) y de las impresoras tridimensionales (cada vez más precisas), han transformado radicalmente la comprensión de la imagen, tradicionalmente ubicada en alguno de los ámbitos (materialidad, transparencia o virtualidad) en los que parecía se encontraba inserta "naturalmente"; han superado incluso la idea de versatilidad asociada a la reproductibilidad técnica de la imagen, al eliminar la condición de pertenencia a uno de dichos ámbitos.

Ahora tratamos con una transimagen capaz de formalizarse en las circunstancias físicas, las coordenadas espacio/temporales y las condiciones 
perceptivas reclamadas por el usuario en cada momento, por lo tanto no pertenece a uno u otro ámbito. Su visibilidad, su apariencia, su constatación perceptiva se han vuelto ocasionales, coyunturales. Poco importa de qué manera ha sido elaborada- en general en procesos en los que intervienen parcialmente cada una de las tres opciones- porque desde su propia invención, desde su comprensión, ya posee la potencia de hacerse presente aleatoria y/o alternativamente como cuerpo material, proyección o matriz numérica. Lo que le caracteriza es la transitividad dígito-material o matero-virtual (uno de cuyos espacios de intersección es la transparencia).

Transitividad entre dos estados nucleares y sus intersecciones, por tanto. Estamos ante una nueva imagen en constante transacción, por cuanto genera interacciones y comercio de datos y cuerpos que se incluyen ahora en nuestra comprensión visual, en la propia percepción. Una imagen transversal que atraviesa diferentes estados, que se teje en el transcurso de su presentación. Imagen en transición, siempre suspendida, siempre de paso, a la espera de ser llamada, en la posibilidad de una nueva re/presentación. Imagen que se transfiere, se transporta a sí misma como otra cosa, se re/convierte, se transforma, se desfigura y se restaura. Imagen que (se) transcribe en un fluir narrativo. Imagen paradójica por cuanto en su emergencia, en su sustanciación, en su presentación participa de la opinión común y a la vez la niega, la quebranta, la transgrede anunciando que no solo es aquello que se percibe. Imagen en estado de transgresión porque contraviene, vulnera la permanencia, la unicidad, la estabilidad que le eran propias, o más bien de las que (ahora lo vemos) se apropia. Imagen de la cesión y del traspaso y por lo tanto muy alejada de aquella imagen de la determinación, la propiedad y la centralidad, que decía lo que tenía que decir, imagen que hablaba "por sí misma".

Esa potencialidad, esa capacidad transitiva, supone un cambio radical en la comprensión y el uso de las visualidades, que ha abierto un nuevo paradigma imaginario (en/con el que vivimos). La nueva dimensión transitiva ha impregnado nuestra manera de tratar con las formalizaciones visuales. Usamos las imágenes en/bajo esta nueva condición de que cualquier síntesis perceptiva posee la potencia de deshacerse en dígitos, proyectarse en luces de color o conformarse en diversas materias; que puede, por tanto, almacenarse en datos informáticos y recrearse en multitud de cuerpos "que permiten a la imagen acceder a la visibilidad” (Belting, 2004).

Las nuevas transimágenes están en disposición de tomar cuerpo, de tomar 
parte de uno u otro medio, de hacerse sustancia y materia, trasparencia o matriz, de adecuarse a la solicitud, a la convocatoria, al anhelo, en la latencia de mostrarse; tienen la potencia -el brío, la facultad, el poder- de reiterar su presencia y de mudar su formalización, están en permanente situación de paso, no pertenecen a un cuerpo sino que circulan volviéndose diferentes entidades, imágenes atravesadas por cuerpos y suspendidas en datos, matrices numéricas y gráficos vectoriales que se convierten, se vuelcan, se traducen, se derraman imagen.

La comprensión del facsímil impreso en 3D como transcripción, a la que se hacía referencia al comienzo de este texto, se interrelaciona con esta traducción matero/numérica, y es esta combinación la que establece la nueva correspondencia y/o tensión del sentido, de la significación y de la presencia entre diferentes inscripciones o impresiones de la misma visualidad ${ }^{4}$.

La circularidad rompe la dicotomía analógico-virtual, la idea de una visión fragmentada del mundo-imagen, en el que cada una ocupa un espacio propio. No se trata solo de que las imágenes, ahora, "naveguen". Ni siquiera de que viajen en el fluir electrónico en la medida en que nosotros las llamamos desde un "terminal". Lo verdaderamente nuevo, insólito, original y extraordinario es que están navegando y a la vez en varios "puertos". Y además, que la entidadimagen tiene la potencialidad de estar en distintos estados, y de hacerlo simultáneamente.

La imagen materia es ahora una contingencia posible que posee la capacidad transitiva, y una interposición tangible de una matriz o un gráfico vectorial. Es la posibilidad material de toda imagen, igual que la imagen digital es la eventualidad matricial de toda imagen, y la imagen transparencia una de las facultades proyectivas de cualquier imagen. Lo que llamamos imagen (que aquí se ha denominado transimagen para subrayar su nueva condición) se constituye en su uso (elaboración, difusión, percepción, intercambio) y por lo tanto en las condiciones en que se muestra para nosotros. Las nuevas imágenes son entidades abstractas y concretas a la vez (potencialmente ambas), que tienen la capacidad de coexistir en varios estados y varios cuerpos. Son entidades con la capacidad de circular y aparecer en diferentes condiciones, no coordinaciones de estados o de partes constituyentes.

En este ciclo, la transimagen posee una renovada versatilidad que potencia de forma extraordinaria la capacidad adaptativa propia de cualquier imagen y por lo tanto (paradójicamente) le incorpora una enorme carga de debilidad, de desconfianza, de incredulidad, de desafección, al "publicitar" su inconstancia, 
al hacer evidente su falta de sujeción en un estado, en una condición, en una significación. ¿Cómo confiar en una imagen que se nos presenta como verdadera, cuando sabemos que habita una red-imágenes circular en la que puede adquirir cualquier cuerpo, insertarse en cualquier relato y escenificarse en cualquier situación? Porque la condición transitiva no es optativa, sino que pertenece a la imagen.

Esta convertibilidad- que es capacidad adaptativa y mutable a su vezatenúa aún más la particularidad sustantiva de las imágenes. La circunstancia de su elaboración en uno u otro medio deja de ser "esencial" en la medida en que el trasvase corporal ha sido integrado en su propia manera de ser. Tendrá sentido como referencia a uno u otro criterio de presentación, a una u otra experiencia productiva y perceptiva, a uno u otro estrato arqueológico en la historia de la construcción imaginaria y de sus proyecciones tropológicas. Su "insustancialidad" es aún más patente.

La peculiaridad reversible de las transimágenes afecta a su corporeidad y a su forma de presentación perceptiva, no a su escenificación o su significación, su contextualización, al juego texto-visual, emotivo y anímico en el que se muestran como imágenes, en el que se les inserta y al que se adecuan, se amoldan y se supeditan. Lo que hace aún más evidente el papel fundamental de estas condiciones perceptivas en la constitución de aquello que identificamos como imagen- en su caracterización, en su delimitación, en la definición de su particularidad.

La nueva condición trashumante de las imágenes, incluso en su versión más literal- la de aquellas que se insertan en un proceso de clonación, porque las herramientas han adquirido ese grado de precisión que permite una multiplicación exacta, por ejemplo, las instantáneas digitales- no elimina la posibilidad preeminente de una de ellas, a la que podemos seguir identificando y llamando "original", pero no porque posea una dignidad de origen o de identidad, o una propiedad específica que la autentifique y la distinga frente a las demás como ella; no por derecho "natural" sino por asignación, porque establecemos unas reglas de priorización ${ }^{5}$. Es ahora una protoimagen; aquella que posee una cierta prioridad o privilegio en relación a las otras posibilidades de ella misma, una preferencia que puede establecerse en base a su identificación, a su uso e intercambio, a su ubicación socio-cultural, etc. Se trata de una "gratificación" que tiene que ver con su finalidad práctica, con su utilización, y por lo tanto, no se genera desde un supuesto centro de control de la veracidad imaginaria, no está sometido a un único designio o a una mirada cierta y verdadera de lo que se ve en ella, sino que se extiende en la 
pluralidad de aplicaciones y accesos que permiten los nuevos medios en red, con la levedad propia de la proyección, la peculiar persuasión de los datos y la indicación de sentido que caracteriza un formato vectorial.

En esta nueva realidad transmedial y líquida que habitamos, la debilidad de la imagen proviene de la desnudez que indicaba la fotografía, aquella experiencia reproductiva que le había quitado su envoltura a la imagen, haciéndole perder su singularidad y atrofiado y triturado su aura (como apuntaba Benjamin), pero descansa ahora en la transparencia con la que se inserta en los modos de significación, la ductilidad con la que participa en los cruces de mediaciones y la candidez con la que pretende mostrarse omnipresente y autosuficiente.

La nueva transimagen no supone una pérdida de la experiencia sino por el contrario una extraordinaria posibilidad de suscitar y difundir experiencias. Nunca antes las imágenes había generado tal cúmulo de posibilidades y oportunidades experienciales, extendidas y libres. Ahora bien, se trata de una experiencia sin ocupación y sin mandato, abierta a la circulación y a la aplicación libre de cada usuario, que la vive en las condiciones que él mismo establece; la que corresponde a una imagen sin espacio propio y sin marcos prescriptivos. Objeto de distintas experiencias, la transimagen reclama, promueve y ayuda a producir un contexto experiencial en el que habita, contexto que no le pertenece ni provoca por sí sola. Las transimágenes se arriesgan en tramas de acontecimientos, de estados, de significaciones, de disposiciones, que las arropan en una u otra dirección. La experiencia ahora no se acumula en la imagen sino que se enhebra en cada una de sus escenificaciones, donde las imágenes además de verse se tocan en un extraordinario fluir de pantallas manoseadas, y se escuchan, es decir, trasladan al espectador los sonidos de sus actuaciones, de sus excitaciones, de sus envíos posibles y efectivos.

No se trata solamente de una recreación/revisión de su capacidad sinestésica, sino más bien del murmullo en el que las nuevas imágenes "navegan", de las condiciones comunicacionales y mediales en las que se entre-tienen, de las vibraciones y las tonalidades de su discurrir-imagen, de los impulsos y las monotonías en las que se insertan y con las que componen; porque ahora podemos oír y tocar el latir de las imágenes. Un latir que nos acompaña y nos muestra una experiencia y un ver con otros, inserto en la memoria y la experiencia del discurrir propio de la imagen-hoy. 


\section{Notas}

${ }^{1}$ Los datos técnicos del proceso de escaneado, impresión y montaje pueden consultarse en la página: http://www.factum-arte.com/pag/295/Un-facs-mil-de-las-Bodas-deCan--de-Paolo-Veronese

${ }^{2}$ Es decir, en su última restauración (hasta ahora), se invirtieron más de dos años, mientras en su realización, Veronese y sus ayudantes tardaron unos quince meses, y la realización del facsímil ha durado trece meses.

${ }^{3}$ Pueden verse en este sentido los comentarios de Jean-Paul Rioux (1998), coordinador del equipo del Laboratorio de Investigación de los Museos de Francia (LRMF).

${ }^{4}$ Para la reconsideración de la idea de traducción, se han tenido en cuenta varios textos. Ver por ejemplo, (Derrida, 2011, pp. 70 y sig).

5 "El problema del origen se funde con el de las causas, las fuentes, los hechos primeros. Si en el pasado bullen infinitos comienzos posibles para todo, entonces ¿cómo encontrar el comienzo de algo? La palabra origen es inseparable de la idea de Dios: supone el inicio primordial de todas las cosas. La figura de un comienzo se sostiene en la decisión (arbitraria pero no injustificada) de fijar una referencia para pensar (...) Kierkegaard conmueve la fatalidad de un origen al desarmar el orden lógico y cronológico de la repetición: no se repite algo ocurrido, sino que la insistencia, que nos asalta una y otra vez, termina por crear su antecedente arrancando algo de la inmensidad, amarrando una presencia a un recuerdo" (Percia, 2012, p.55).

\section{Referencias}

Arrault, V. (2006), "La barbarie enchantée”, en La création artistique face aux nouvelles technologies (Séminaire Interarts de Paris 2004-05), París, Klincksieck

Belting, H. (2004), "Images trop plein, vide, manipulations, imagerie numerique: à quoi tient la crise de la représentation?", en Telerama 2868.

Belting, H. (2007), Antropología de la imagen, Buenos Aires y Madrid, Editorial Katz

Brea, J. L. (2005), Estudios visuales. La epistemología de la visualidad en la era de la globalización, T.C. Madrid, Akal.

Deleuze, G. (2013), El saber: Curso sobre Foucault, Buenos Aires, Cactus.

Derrida, J. (2001), La verdad en pintura, Buenos Aires, Paidós.

Derrida, J. (2011), "Yo - el psicoanálisis", publicado en Cómo no hablar, y 
otros textos, Barcelona, Anthropos editorial Didi-Huberman, G. (2013), L'image ouverte, París, Gallimard Jay, M. (2004), Campos de fuerza. Entre la historia intelectual y la crítica cultural, Barcelona, Ediciones Paidos ibérica.

Jaschko, S. (2010), La performatividad en el arte y la producción de

presencia, exposición "El proceso como paradigma" en Laboral, Centro de Arte y Creación Industrial, Gijón, España.

Larrañaga, J. (2011), "La imagen instalada" en la Revista Re-visiones 1, p.8:

http://www.imaginarrar.net/descargas/Laimageninstalada.pdf

Metz, C. (2001), El significante imaginario, Barcelona, Paidós

Percia, M. (2012), "Un oído que está por aparecer”, en Blanchot, M. (2012)

La palabra analítica, Buenos Aires, Ediciones La Cabra

Rioux, J.-P. (1998), Revista Techné, 7, p.95

Virilio, P. (1998), La máquina de visión, Madrid, Ediciones Cátedra.

Yáñez Tapia, G. (2007), "Imagen digital: la suspensión de la distancia categorial moderna”, en Revista Estudios Visuales, 5

Josu Larrañaga Altuna: Catedrático de Pintura, Facultad de Bellas Artes. Universidad Complutense de Madrid.

Contact Address: Calle Greco 2, 28040 Madrid (España).

E-mail address: josularranagaaltuna@gmail.com 